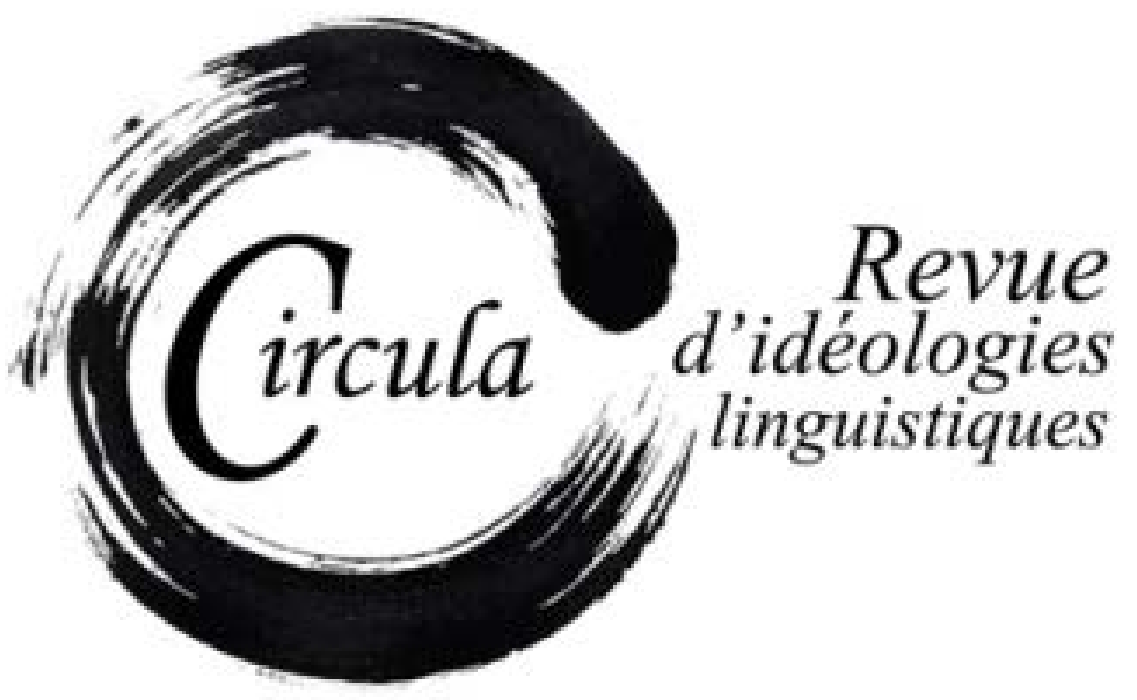

TITRE: LENGUA ESPAÑOLA E IDEOLOGÍA CRIOLLA EN LA NUEVA ESPAÑA: DEFENSA DE LA PRONUNCIACIÓN COMO ELEMENTO DE REIVINDICACIÓN

Auteur(s): José Martín Hidalgo Martínez, Universidad Autónoma Metropolitana

Revue: Circula, numÉRo 8 - IDEOlogías en obras sobre LA LENGUA eSPAÑola (SS. XV-XX)

PAgES: $129-146$

ISSN: 2369-6761

Directeurs: : Francisco Escudero Paniagua, Carlos Villanueva García, Carmen Quijada Van DEN BERGHE, José Jesús Gómez AsEnCIO

URI: HTTP://HDL.HANDLE.NET/11143/15554

DOI: HTTPS://DOI.ORG/10.17118/11143/15554 


\title{
Lengua española e ideología criolla en la Nueva España: defensa de la pronunciación como elemento de reivindicación ${ }^{1}$
}

José Martín Hidalgo Martínez, Universidad Autónoma Metropolitana

martilhid@gmail.com

\begin{abstract}
Resumen: La sociedad novohispana se vio envuelta en una compleja situación social que provocó conflictos entre los distintos sectores que la componían. Uno de los grupos más activos ante esta situación fue el criollo, el cual emprendió un proyecto de reivindicación que lo llevó a construir su propia identidad a través de un discurso en que se presenta a sí mismo como el elemento transformador de la sociedad en la que vive. La construcción de su identidad pasó por el ámbito lingüístico, su postura respecto a sus particularidades lingüísticas provocó desavenencias con otros grupos, las cuales se plasmaron en una polémica publicada en uno de los periódicos más importantes de la época, el Diario de México.
\end{abstract}

Palabras clave: criollismo; pronunciación; polémica; identidad

Abstract: The society of New Spain was involved in a complex social situation that provoked conflicts between the different sectors that made it up. One of the most active groups was the criollo, which undertook a project of vindication that led him to build his own identity through a discourse in which he presents himself as the transformed element of the society in which he lives. The construction of its identity passed through the linguistic field, its position with respect to its linguistic particularities caused disagreements with other groups, which resulted in a polemic published in one of the most important newspapers of the time, the Diario de México.

Keywords: criollismo; pronunciation; controversy; identity

1. Este trabajo forma parte de la tesis "Lengua: orden e insubordinación. Polémica en torno a la pronunciación del español en el Diario de México" de la maestría en Humanidades, línea Lingüística, presentada en la Universidad Autónoma Metropolitana, Ciudad de México, 20 de julio de 2016. 


\section{Introducción}

La Nueva España abarca el periodo entre los siglos XVI y las primeras décadas del siglo XIX. En tal lapso se desarrolló una sociedad que se complejizó debido a distintos factores, entre ellos, la heterogeneidad de su población, el surgimiento de identidades diferenciadas, una dinámica administrativa en que se creaban vacíos de poder y, sobre todo, la creciente confrontación entre los distintos grupos que la componían.

La estratificación de los novohispanos y su división en castas no hacían más que aumentar la polarización por causa de un desigual acceso al desarrollo. Los diversos sectores sociales que la componían estaban ordenados jerárquicamente: en la parte más alta de esta clasificación se encontraban los peninsulares, la población europea llegada al continente americano. Los criollos ocupaban el segundo peldaño en la escala social y, por debajo de estos, se encontraban los indios y la población mestiza. Al final de la estratificación se encontraban las distintas castas.

Desde los primeros años de presencia europea en el continente, se comenzó a hacer una distinción entre la población europea y sus descendientes, las nuevas generaciones de población blanca nacida en América. De esta situación se desprende la primera definición de criollo: los descendientes de españoles nacidos en América. Esta definición era asumida por los mismos criollos y en parte se mantuvo hasta los últimos días de la colonia, de manera que el criollo se llamaba a sí mismo español americano.

Los criollos tenían un estatus especial, pues por tratarse también de población blanca disfrutaban de ventajas sobre otros grupos sociales. Sin embargo, sentirse europeos, pero no ser considerados como tales comenzó a crear un descontento en la población criolla. Su enojo aumenta al verse desposeído de derechos que considera suyos, en primer lugar, su derecho a ser español. De este conflicto surge la segunda definición de criollo, la cual no procede del hecho de haber nacido en América, sino de un hecho voluntario, un acto de elección personal. Esta definición comenzó a surgir a partir del siglo XVII como producto de reconocerse habitante del Nuevo Mundo y concebir una identidad propia a partir del engranaje de un conjunto de elementos de toda índole, desde el paisaje y las nacientes tradiciones, hasta el surgimiento de expresiones artísticas y culturales que acusaban una personalidad propia y que el criollo no tardará en destacar y promover, pues el mismo criollo comenzó a concebir el criollismo como un orgullo y una virtud.

Estas formas de entender el criollismo fueron señaladas por Edmundo O'Gorman: a su entender, debía superarse la mera concepción racial del término, esto es, los criollos como descendientes de europeos, para concebir el término de manera más amplia, más bien como: 
Progresiva resultante de un secular y complejo proceso de inventiva histórica impulsado por la necesidad vital de albergar en el corazón dos lealtades en principio opuestas, la de cómo pertenecer en cuerpo y alma a España la vieja, sin dejar de ser en alma y cuerpo hijo de la Nueva España: dramática ambivalencia de dos orgullos sólo reconciliable en el seno de una visión del acaecer universal que incluyera, pero con signo positivo, la historia precristiana del Nuevo Mundo (O'Gorman, 1972: 13)

Tal concepción del criollo permite entender la construcción de un discurso nuevo, pues desde el primer momento en que el europeo ocupa el nuevo continente, las nuevas generaciones comenzaron a hacer suyas las tierras americanas. Así surge una identidad ambivalente que, con el paso del tiempo, se fraguó como identidad propia, heredera de la española, pero definida por la nueva realidad en la que vive. La construcción de la identidad criolla se vio estimulada por el ámbito político y la dinámica social en que se enfrentó a los peninsulares, sector más consolidado en los espacios de poder y la administración de la colonia. En el enfrentamiento también la temática lingüística ocupa un lugar importante, pero se hace explícita al final del periodo colonial en el primer periódico de publicación cotidiana en la capital de la Nueva España, el Diario de México, medio de comunicación que admitía la participación general, pero en el que los criollos tenían una participación destacada.

\section{Construcción de la identidad criolla}

Aunque este diario comienza a publicare en el mes de octubre de 1805, en la última etapa del dominio español en América, en realidad forma parte de un largo proceso de conformación de la identidad criolla. Ese proceso que para inicios del siglo XIX llega a su cenit, se remonta, para algunos autores (O’Gorman, 1972; Brading, 1973), a las primeras décadas de la llegada al continente y para otros (López Cámara, 1969; Villoro, 2002) es un proceso que se desencadena, principalmente, en el siglo XVIII cuando aumenta el descontento en esa población por el endurecimiento de las políticas de control sobre la colonia.

A partir de las Reformas Borbónicas impuestas para mejorar la administración, los criollos sintieron mermado su acceso a espacios en la gerencia, el gobierno y la economía. Tales limitaciones fortalecieron el proceso de conformación de la identidad criolla para reafirmar su convicción de ser merecedor del derecho a autogobernarse. El criollo sustenta ese derecho en viejas legislaciones ${ }^{2}$ y en un fuerte sentimiento de arraigo a las tierras americanas que, para inicios del siglo XIX, le proveen de una visión propia sobre su futuro y su papel en América. El sentimiento de ser español americano y poseer particularidades culturales e históricas que lo ligan a la tierra en que nació dio como resultado una afirmación de sí mismo cada vez más abierta y explícita en un discurso que se plasmó en

2. Un ejemplo al respecto se menciona en El proceso ideológico de la revolución de independencia al referir la crisis política de 1808 en la Capital de la Nueva España cuando ante la inestabilidad ocasionada por la invasión napoleónica a la Península española, los criollos proponen remitirse a la Carta Magna de Castilla redactada por Alfonso el Sabio siglos atrás para solventar el vacío de poder mediante el autogobierno (Villoro, 2002: 39). 
obras literarias, históricas y que tuvieron en las publicaciones periódicas su vía de expresión más directa. El Diario de México, en ese sentido, es el recipiente en el que el criollo vertió su pensamiento y planes sobre la nueva sociedad a la que aspira.

Para explorar la conformación de la identidad criolla en el ámbito lingüístico, nos centramos en un extenso debate que se desarrolló por más de cuatro años en dicho periódico. En ese debate participaron al menos una veintena de individuos letrados provenientes de distintos estratos sociales y culturales ${ }^{3}$. Puesto que la mayoría de los participantes en la discusión firman sus escritos sin nombre propio ${ }^{4}$, es difícil, salvo algunas excepciones, precisar quién se encuentra detrás de cada colaboración ${ }^{5}$. Sin embargo, el contenido del texto y la posición u opinión que asume cada autor respecto de la lengua española hablada en la Nueva España, que en su mayor parte se centra en la pronunciación, permiten agrupar el conjunto de textos de manera clarificadora, suficiente para observar cuáles son los aspectos en conflicto.

A partir de esta clasificación de opiniones, es posible ordenar las ideas lingüísticas que sustentan las ideologías lingüísticas que se encuentran en pugna. La distinción de estas ideas lingüísticas, sin embargo, no puede ser entendida sin la debida contextualización en un espacio y tiempo determinados, por ello su interpretación requiere de una adecuada imbricación con el panorama histórico en que se producen. Con este propósito partimos de acercamientos previos al criollismo o nacionalismo criollo con la intención de conectar la dinámica social y política a partir de la cual se originan las confrontaciones entre grupos sociales que componen la heterogénea sociedad novohispana.

Siguiendo a Van Dijk (2006: 19), al observar las manifestaciones discursivas de una sociedad es posible conocer la apariencia de las ideologías, cómo se crean y reproducen. En el caso de la sociedad novohispana, uno de los sectores con mayor acceso al discurso público era el criollo, por tanto, las manifestaciones discursivas que componen el corpus de análisis en el presente artículo serán no de una sociedad en su totalidad, sino sólo de una parte, la compuesta por los criollos, y es precisamente este el discurso al que damos seguimiento en la polémica sobre la pronunciación. Centramos nuestra curiosidad en la relación que se establece entre el ámbito lingüístico y el político-social.

3. Algunos de los textos que componen la polémica que analizamos presentan rasgos que hacen suponer una posible
recreación de la discusión, por ejemplo, cuando se introducen o se refieren diálogos acaecidos en otro momento y cuya
temática es considerada delicada, lo que interesa a sus autores poner en voz de otros tales dichos como forma de la
posible censura o, incluso, la sanción por parte de las autoridades. También es posible que se incurra en la recreación
del diálogo mediante la participación de un mismo autor bajo distintos seudónimos con la intención de llevar a discu-
sión pública temáticas de interés y, con la libertad que provee este recurso para dirigir el curso de la conversación y sus
conclusiones. Este recurso se aprecia en varios de los escritos que son atribuidos a y firmados por individuos llamados
payos, personajes de condición social y cultural baja, para descalificar sus opiniones y papel en la sociedad mediante la
exhibición de sus carencias en el uso de la lengua tanto oral como escrita.

4. Algunas veces con un seudónimo, otras con las iniciales del nombre de algún personaje importante en la vida social o cultural en la capital de la Nueva España y, otras más, con un acrónimo.

5. Para la importante labor de identificar a los polemistas fueron de gran utilidad Ester Martínez Luna (2002) y Carmen Ruíz Castañeda (2000) 
Nos interesa describir la confrontación entre dos grupos sociales que origina dos discursos sobre la lengua española en la Nueva España.

En los primeros dos siglos de colonia, los criollos desarrollaron una economía fructífera que los encumbró económicamente y los colocó en posición ventajosa ante el resto de la población. Mientras los indios se ubicaron en los espacios destinados exprofeso para ellos, los pueblos de indios como espacio geográfico que limitaba su margen de acción, los criollos desarrollaron una intención abarcadora en la Nueva España. Extendieron los vínculos entre las múltiples ciudades y pueblos más importantes, lo que produjo un contacto continuo y creciente que los mantuvo aglutinados por medio de las obras literarias, las publicaciones periódicas, el intercambio y la movilidad de la población criolla así como los vínculos comerciales. Tal interacción les dio una fuerte integración de clase que los otros sectores sociales sólo lograrían, y de forma muy disminuida, a partir de los tiempos del México independiente.

Durante el siglo XVIII se sucede en la Nueva España un hecho trascendental para el actuar del crioIlo: la aplicación de las reformas borbónicas que limitan aún más su acceso a puestos que en otro momento había ocupado. Se trató de reformas con las que desde la Península se intentó recobrar el control de una colonia que se consideraba ya fuera de alcance, con fugas, despilfarros y saqueo de la propiedad real. Por tal motivo se intentó mejorar la eficiencia mediante la reestructuración de todo el aparato administrativo.

La visita que José de Gálvez realizó entre 1765 y 1771 a la Nueva España y la consiguiente inspección pormenorizada del territorio, determina que la administración deficiente ocasiona no sólo pérdidas económicas a la Corona, sino la ruptura de las cadenas de mando y la carencia de un control confiable y benéfico para el reino. Por tal motivo es necesario "Recuperar los hilos que con independencia del reino movían desde hace más de medio siglo los mecanismos económicos, políticos y administrativos de la colonia, colocarlos bajo la dirección y vigilancia de hombres adeptos a la metrópoli, y hacerlos servir a ésta por sobre cualquier otra consideración” (Florescano y Gil Sánchez, 1998: 492).

El dictamen de José de Gálvez se encamina a recomendar el papel de subordinado que deberían adoptar en adelante los criollos. Es así como son removidos de los puestos centrales o de mando y sustituidos por peninsulares, lo que agranda severamente el descontento. En respuesta, los criollos fortalecen su proyecto más importante, un plan sociocultural concretado en la interpretación y la reescritura de su historia en tierras americanas, convencidos de que nunca recibirán un trato de iguales.

La tarea de reivindicación comienza con obras literarias e históricas en las que se presenta al criollo con la importancia que siempre ha anhelado, la de ser centro y partícipe de su destino por poseer un pasado propio y un capital de virtudes que comienzan, en primer lugar, por ser ellos descendientes de europeos, hecho que los ubica por encima del resto de los habitantes indios, negros y mestizos. En segundo lugar, su bagaje cultural, pues debemos recordar que la mayor parte de los letrados, 
tanto laicos como religiosos, son de origen criollo, por ello ocuparon, hasta antes de las reformas, cargos de importancia en el clero, las cátedras en la universidad, los puestos más importantes en la administración pública y el gobierno, así como cargos de alto rango en el ejército.

Su cercanía a las letras y otras expresiones culturales, debido a la posibilidad casi exclusiva de acceder a educación formal, impulsa al criollo a comenzar a concebirse como el personaje que tiene el deber de transformar su sociedad. Como parte de tal transformación promueve, entre muchas otras obras culturales, la publicación del Diario de México y resume sus intenciones en el primer número del periódico con la frase: "civilizar a la plebe y reformar sus costumbres" (DM, 2 de octubre de 1805). Educar y civilizar es precisamente el propósito que se manifiesta también en las muchas polémicas en las que los inconformes expresan su descontento en diversas temáticas, las cuales consideran susceptibles de poner a discusión, pues, como un colaborador expresa: "con la imaginación y el debate se ventilan y aclaran las materias..." (DM, 14 de mayo de 1806).

Durante todo el siglo XVIII es claro que el sector criollo es el más apto para emprender una labor de tal envergadura y, en cierta manera, le resulta más fácil, pues ha comenzado desde los primeros años del periodo colonial, sin imaginar cuánto se prolongará su reclamo para ser tomado en cuenta. En un principio, la dificultad en la construcción de su identidad radica en el hecho de suponer que con el tiempo logrará el éxito en sus esfuerzos de ser incluido nuevamente en el desarrollo económico y personal que le han arrebatado las reformas. Posteriormente, cuando se percata de que sus esfuerzos son y serán infructuosos dado el rechazo y el aislamiento al que ha sido sometido, emprende la construcción de su propia historia. Se trata de la construcción ideológica de su ser y su destino en el mundo.

Uno de los puntos nodales al construir su identidad es su toma de conciencia de la discriminación de que es objeto, puesto que existe una negativa a reconocerlo como igual, y por ello optará por establecer históricamente su origen. El resultado final del diseño de un pasado histórico alterno, adquiere un matiz mítico al conectar su presente ya conocido ${ }^{7}$, con el pasado de las grandes culturas indígenas, promoviendo con ello su equiparación con España, pero sin ligarse directamente con ella. Este proceso ha sido llamado criollismo o nacionalismo criollo.

Surgen así obras que explican el supuesto origen precristiano del Nuevo Mundo, por ejemplo, en el Sermón Guadalupano escrito en 1794 por fray Servando Teresa de Mier, donde establece tres aspectos primordiales sobre los cuales descansa la narrativa histórica y religiosa que propone para sí: primero, que la evangelización de los indios comenzó, no en el siglo XVI, sino en el siglo primero de nuestra era; que fue realizada no por las distintas órdenes religiosas que llegaron a América después de la Conquista, sino por santo Tomás como una advocación del dios prehispánico Quetzalcóatl y, finalmente, que la toga o ayate del indio Juan Diego en la que se plasmó la Virgen de Guadalupe,

6. Abreviamos Diario de México como DM para facilitar la lectura de la referencia.

7. El pasado histórico que consiste en que los criollos son descendientes de los europeos llegados al Nuevo Continente. 
según la tradición cristiana, era en realidad la capa de Santo Tomás que le fue retirada a los indios por temor a que estos la maltrataran. Después, continúa Teresa de Mier, la misma fue entregada a Juan Diego, alrededor de 1530, unos años después de la Conquista para pedir al obispo fray Juan de Zumárraga construir la basílica de Guadalupe.

Las interpretaciones históricas criollas se incluyeron en otras obras, como la Historia antigua de México de Francisco Xavier Clavijero, Historia antigua de México de Mariano Fernández de Echeverría y Veytia, en Instituciones Teológicas de Francisco Javier Alegre, y obras periódicas como el Mercurio Volante de José Ignacio Bartolache (Moreno Bonett, 2000: 68). Entre estos escritos, puede incluirse el Diario de México, publicado entre 1805 y 1817, en el que continuó la intención de reivindicar la historia y cultura criolla y su relación con el pasado prehispánico. Una relación más de índole política que verídica, pues tal construcción histórica plantea la posición política de los criollos: su convicción de que el derecho a autogobernarse proviene del carácter autóctono del criollo.

\section{Dos grupos criollos}

La diferencia entre las obras anteriores y lo expuesto en el Diario, es que en este último se plantean las posibilidades de una nueva sociedad encabezada por el criollo, desde luego, exponiendo tales intenciones con las provisiones y cautela que ameritan tan delicadas propuestas. Como veremos enseguida, su propuesta de lengua española también forma parte del plan de transformación y de su proyecto de distinguirse del peninsular.

A finales del siglo XVIII, las posiciones se radicalizan a raíz de las ya mencionadas reformas y de otros sucesos de carácter económico: sequías, hambrunas, desplazamientos poblacionales, desempleo, e incluso algunos levantamientos que son sofocados rápidamente (Florescano y Gil, 1998: 579; Florescano y Rojas, 1996: 35). Es en este momento, últimos años del siglo XVIII y primeros años del XIX, que se puede apreciar que el grupo criollo no es del todo uniforme, sino que en su interior coexisten dos perspectivas respecto del régimen: los criollos colonialistas y los criollos insurgentes (López Cámara, 1969: 201). El primero es simpatizante del régimen, mantiene sus demandas, pero su objetivo es mantener sus ligas con la Corona y la institución colonial; mientras que el segundo, apunta sus intenciones a la autonomía y asumir el control del territorio dadas sus cualidades, esas que han quedado establecidas mediante la intrincada construcción de su espíritu y personalidad que brevemente han quedado resumidas líneas atrás.

La confrontación entre estas dos posturas se refleja en el nuevo periódico que funge como su órgano de comunicación, pues el Diario tiene el objetivo de contribuir con su programa de auto identificación. Los contenidos del periódico están encaminados a fortalecer las ideas criollas sobre la suficiencia de sus capacidades y se constituye como una herramienta más para incidir en la aceptación del criollo como la columna vertebral de la vida social novohispana. 
En el periódico quedaron retratadas las ideas lingüísticas de varios grupos sociales, primordialmente las de los dos grupos criollos, por ser ellos los mejor preparados para incursionar en el discurso público al poseer una educación formal de la que carecían otros, por ejemplo, los indios. Las opiniones expresadas por distintos individuos condujeron a una polémica sobre la pronunciación y otros temas relacionados con el idioma.

La oposición entre unos y otros deja ver que detrás de las opiniones sobre la lengua y sus hablantes está la misma sociedad polarizada que hemos descrito. Esa situación obliga a los distintos grupos sociales a tomar posición, pues en el contexto de confrontación previo a la lucha por la independencia el campo lingüístico no está exento de la acción política. Por tanto, la lengua se convierte también en un espacio de disputa y esas opiniones respecto a cuál debería ser su uso se plasman en la polémica sobre la pronunciación.

\section{Polémica sobre la pronunciación}

Aunque desde el primer número del Diario aparecen opiniones sobre la lengua, es a partir del número 40 cuando se expresa de manera explícita el descontento por parte de un polemista. Este personaje firma como "El Criollo Mexicano" y es con sus opiniones con las que efectivamente comienza la discusión. Dice en tono vehemente: "Señor Diarista: pretendo saber por usted o por otro que lo sepa, ¿cuál es el motivo por el que nosotros los criollos en general no pronunciamos con perfección nuestro idioma español?" (DM, 9 de noviembre de 1805: 166) ${ }^{8}$.

\section{SBior Diarista: Pretendo saber por V. ó por otro que lo sepa tqual

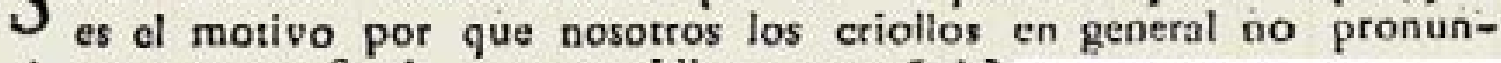 ciamos con perfeccion nuestro idioma español ?}

De la misma manera, expresa enseguida una consecuencia de forzar la pronunciación, aspecto que, años después, sería destacado por Domingo Faustino Sarmiento en la polémica que mantuvo con Andrés Bello: el escarnio al que eran sometidos los habitantes de la Nueva España al forzar su pronunciación para mantener rasgos fonéticos de la pronunciación peninsular como el ceceo: "o porque aunque algunos hacen alarde de saber charlar, pronunciando las zetas, las ces y las elles, se nos murmura por nuestros mismos paisanos, atribuyendo a faramalla, lo que debía ser una buena recomendación en un criollo?". Concluye su participación en el Diario y dice:

Los reclamos y aspiraciones del Criollo Mexicano se extienden por gran parte del número 40 del Diario. La respuesta a estas preguntas y reclamos aparece algunos días después, el 3 de diciembre

\footnotetext{
8. En las siguientes páginas incluimos otros fragmentos del Diario de México que también forman parte del debate. Sustituimos algunas citas textuales por la imagen digitalizada del documento original con el propósito de ilustrar el discurso que analizamos y proveemos la referencia de la misma en el párrafo previo a cada imagen.
}

9. En el caso de la polémica entre Bello y Sarmiento, los habitantes del sur del continente americano. 


\section{¡Que gloria sería para la N. E. igualarse en esta materia con la Metrópoli, y que resonára en ses distritos el agradable soti- do do la verdadera lengua casteliana, oyendo pronunciarla á lós es- pañoles americanos con toda la excelencia de que es susceptible}

del mismo año, en una extensa carta de otro polemista que firma con el seudónimo Escuelero de Tierradentro ${ }^{10}$. Esta contribución al debate presenta características particulares y muchas aristas para discutir; por ejemplo: se trata de una carta que en apariencia tiene el objetivo de sumarse al reclamo del Criollo Mexicano, pero le da voz en la mayor parte del escrito a opiniones contrarias al mismo. Así, en la primera parte de su carta se adhiere a la opinión expuesta anteriormente: "En el Diario número 40 pregunta un Criollo Mexicano ¿por qué los más de sus paisanos pronuncian tan mal el idioma? Yo también me lo he preguntado..." (DM, 3 de diciembre de 1805: 267). Sin embargo, pese a esta primera afirmación, la mayoría de su muy extenso escrito ${ }^{11}$ da cabida a opiniones contrarias a las del Criollo Mexicano, lo que despierta la duda de cuál es la verdadera intención de este polemista, apoyar al Criollo Mexicano u oponerse a él.

El Escuelero de Tierradentro expone sus opiniones mediante un supuesto diálogo ${ }^{12}$ que mantuvo en el pasado con un alumno. En el texto se intercalan las dos voces, separadas mediante guiones, como se observa en el extracto siguiente:

En primera intención, la opinión del Escuelero es que debe reformarse la pronunciación de los criollos y asimilarla a la peninsular, cuando dice que hay que "asimilarla a la de nuestros mayores" y precisa:

\section{; Y quienes son esos sipo los zachu-} pincs, que nos engendraron $y$ nos dieron sa lengua ? ¿No será bueno perfeccionarla nosotros como los que mejor la hablan en la penínsola? - Entre nosotros posa ese esfcerso por pedanteria y ridicoles ¿Y por qué? ¿ por que aspiranos à la perfescion?

“iy quiénes son esos sino los gachupines, que nos engendraron y dieron su lengua? ¿No será bueno perfeccionarla nosotros como los que mejor la hablan en la península?” (DM, 4 de diciembre de 1805: 274). Sin embargo, la mayor parte del texto del Escuelero está dedicada a exponer las respuestas y afirmaciones de su alumno, por ejemplo, cuando dice del intento por reformar la pronunciación: "Entre nosotros pasa ese esfuerzo como pedantería y ridiculez..., y concluye: "Yo sigo la costumbre de mis paisanos, que todos hablan como yo".

10. El término escuelero se aplicaba, de forma despectiva, a los profesores de primeras letras.

11. La extensión del texto es tal que debe publicarse en tres partes en sendos números del periódico correspondientes al 3, 4 y 5 de diciembre de 1805.

12. Como se ha apuntado anteriormente, se trata de un recurso común para eximir de culpa al autor por exponer ideas que podrían considerarse delicadas o comprometedoras. 
De la discusión entre el Escuelero y su alumno también se desprende información sobre lo que estos dos grupos de criollos en conflicto piensan sobre otras realizaciones del español en la Nueva España, sobre todo en el habla de los indios y los mestizos. Cuando el Escuelero pregunta a su alumno por qué si este dice hablar como sus paisanos entonces por qué no emplea expresiones usadas por otros hablantes; ante tal duda pregunta: "¿Por qué no dice usted yo vinía a que usted me destruyera en el catasismo, porque donde prencipio que vino a la ciudá mi agüelito me quería tráir, pues no deja de inorar sus obligaciones y él está opuesto a lo que usted mande?" (DM, 4 de diciembre de 1805: 275). Es decir, el Escuelero inquiere por qué no habla como las mayorías iletradas si también estas son americanas y, por tanto, se trata también de sus paisanos. A esta interrogante el alumno responde que el habla que defiende no es esa y concluye enumerando las causas de su opinión:

\section{Por que ese es un lenguage grosero, iosignificante, solo uss- do entre la gente idiota $y$ rústica}

Precisa que su desacuerdo se centra en las diferencias entre el español criollo y el peninsulary dice:

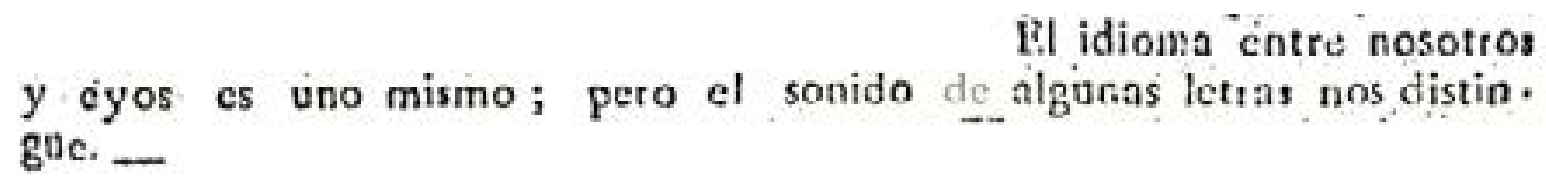

Es importante mencionar el uso de dos modelos ortográficos distintos a lo largo de la polémica, pues este hecho no es resultado de una casualidad. El caso del texto del Escuelero, dependiendo de quién hable en el diálogo aparecerá escrito ellos/eyos; parecer/pareser; criollos/crioyos con la intención de hacer palpable la diferencia entre dos formas de pronunciar. En el caso de otros polemistas es una forma de posicionarse ante disyuntiva que se discute, por tal motivo aparecen las grafías que representan los sonidos en conflicto: s, c, z, y, ll y el empleo entre una y otra grafía responde a la posición que se asume y el bando con el que se simpatiza. Otros ejemplos semejantes son los siguientes:

\begin{tabular}{|c|c|}
\hline Ortografía americana & Ortografía española \\
\hline despresio & desprecio \\
\hline yamamos & llamamos \\
\hline dise & dice \\
\hline seta & zeta \\
\hline esfuerso & esfuerzo \\
\hline juisio & juicio \\
\hline veses & veces \\
\hline cartiya & cartilla \\
\hline yamarse & llamarse \\
\hline
\end{tabular}


La respuesta del alumno deja claras dos cosas: primero, que hay una división entre la opinión de los dos grupos de criollos - uno opina lo que hemos visto, que el habla de los criollos es viciosa y hay que corregirla; otro, que hay que respetarla así como se manifiesta en la Nueva España-; segundo, que en este grupo criollo que, si bien aboga por el respeto a los usos de la lengua en la Nueva España, su defensa no se refiere a la totalidad de la población, sino sólo al grupo que se ha fortalecido y propugna por mayores libertades. Es el grupo criollo que largamente ha conformado su identidad y construido su legitimidad para autogobernarse basado en la reelaboración histórica de su presencia en América. Es el grupo que ha puesto en su plan de acción, para el futuro próximo, la transformación de la sociedad; es la facción de la sociedad criolla inconforme con el régimen y que tiene un ala ilustrada que es la que se manifiesta en la polémica.

Aunque la polémica se prolonga por varios años, en realidad el conjunto de opiniones posteriores puede ser englobada en las que manifiestan los dos textos expuestos y el que reseñamos a continuación, pues en ellos se hacen presentes las tres principales realizaciones de la lengua española en ese momento y espacio histórico: el habla criolla propia de un grupo criollo simpatizante con el régimen; el habla del grupo criollo inconforme que ve en las particularidades de su realización lingüística un elemento más de la construcción de su identidad y, finalmente, el habla de las mayorías de origen indio y mestizo hablantes de español que, a juicio de los dos grupos criollos anteriores, está llena de vicios y deficiencias.

Para complementar las posturas presentadas, incluimos a continuación la opinión de otro colaborador más, quien por las características de su escrito, así como por el seudónimo con el que firma, expone otra de las perspectivas involucradas en la polémica. Se trata del Criollo Otomí, el seudónimo Criollo Otomí13 delata su posición en el espacio social del personaje real que lo esgrime. Este polemista, por una parte, comienza criticando fuertemente al iniciador de la polémica, el Criollo Mexicano, diciendo que él no es mexicano, clara alusión al corte colonialista de su propuesta. Recordemos que el Criollo Mexicano representa (junto con otros que se suman a su propuesta) al grupo criollo que simpatiza con el régimen y propugna por asimilar la pronunciación de la lengua española en la Nueva España con la peninsular. Por tal motivo, este nuevo criollo recela del calificativo "mexicano" que se ha endilgado un criollo mexicano que, paradójicamente, se quiere asimilar a los "gachupines" (DM, 12 de marzo de 1806: 322).

Con ello en mente, el Otomí intenta denunciar la ignorancia de los que han participado en el desarrollo de la discusión y se han erigido como censores de la lengua española en la Nueva España. Dice más adelante que, al hacer uso de la lengua en su modalidad escrita, ese fementido criollo por su ignorancia y: "por el qué dirán consulta, pregunta, y aun enseña su carta a un amigo castellano viejo; éste se la corrige y si tiene tiempo la traslada, y si no, en todas aquellas partes en donde ha puesto $z$ por coc por zo z por s o s por zo c por s o s por c o y por ll, o ll pory, les deja caer un borroncito para

13. Los otomí son una etnia indígena de lengua otomí o ñahnú ubicada al norte de la capital de la Nueva España. La lengua otomí fue una de las lenguas generales muy importantes durante la colonización. 
que duden lo que es", todo ello en alusión a quienes piensan que dominan con destreza la lengua española, en realidad también incurren en errores y desatinos, al igual que las mayorías que tanto critican.

En su totalidad, el texto está dedicado a criticar a los criollos que simpatizan con el español castellano y que intentan sumar la normatividad lingüística a las ya cuantiosas disposiciones reales que sujetan la colonia a la metrópoli, limitando con ello más uno de los pocos reductos de libertad, el del habla.

Como forma de dirimir la disputa sobre cuál debería ser la pronunciación adecuada en la Nueva España, se invoca el respaldo de los grandes gramáticos, por ejemplo, de Antonio de Nebrija. En el texto publicado en el número 119, correspondiente al 27 de enero de 1806, un participante que firma con las iniciales LP, opina que el yeísmo y el seseo son los principales defectos que los criollos deben corregir. Por tal motivo, se pregunta:

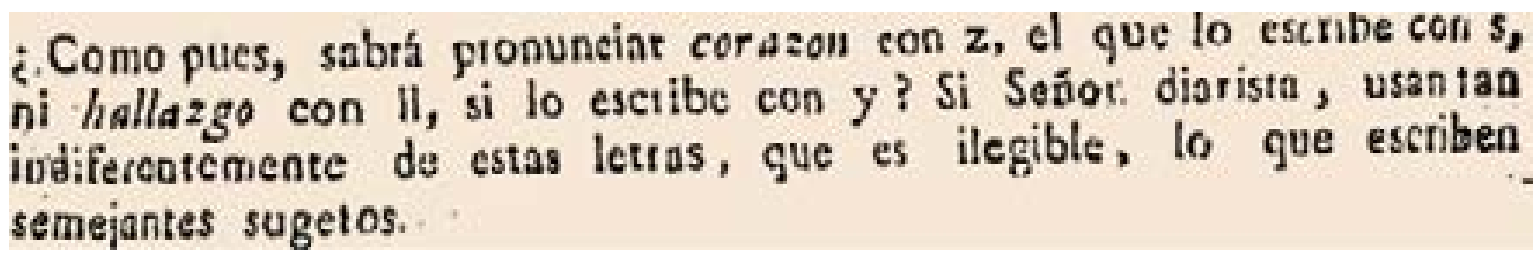

Ante tal problema, al final de su carta sugiere al director del Diario:

\section{digales con Diso Antonio Nebrija, gúé la bikena fro- nunciacion depende de la buena ortografis $=$ L. P. (2)}

La continua correlación entre la pronunciación y la ortografía se esgrimió, incluso, desde los primeros números del Diario cuando un lector se inconformó a causa de dos palabras escritas sin atender la regla ortográfica:

¿Que concepto harán del talento americano aquellos sabios ultramarimos, al ver que en un papel público impreso ca Mexico se esaribe COLICEO OLANDIiZA, y no se
menciona el trigo entre los viveres de mayor consumo en esta $\mathrm{Ca}$ pisal? (*)

La reclamación pareciera ser insustancial, a no ser porque en tal reclamo aparecen dos de los sonidos que días después serán el centro de la polémica: $/ \mathrm{s} /$ y $/ \mathrm{\theta} /$. El lector inconforme aduce la falta de credibilidad y pérdida de prestigio americano si se cae en tales errores, aunque no queda claro si también hay descontento porque la escritura de Coliseo con s y Olandeza sin h y con z intenta proponer o descalificar una cierta pronunciación. Para el grupo criollo que buscaba imponer la pro- 
nunciación peninsular en la Nueva España, la solución se limitaba a difundir las reglas ortográficas, y por tal motivo se publicaron compendios breves de la normatividad y como forma de facilitar su difusión y aprendizaje se incluyeron en el Diario textos en verso para promover la memorización en los lectores:

\begin{tabular}{|c|c|}
\hline 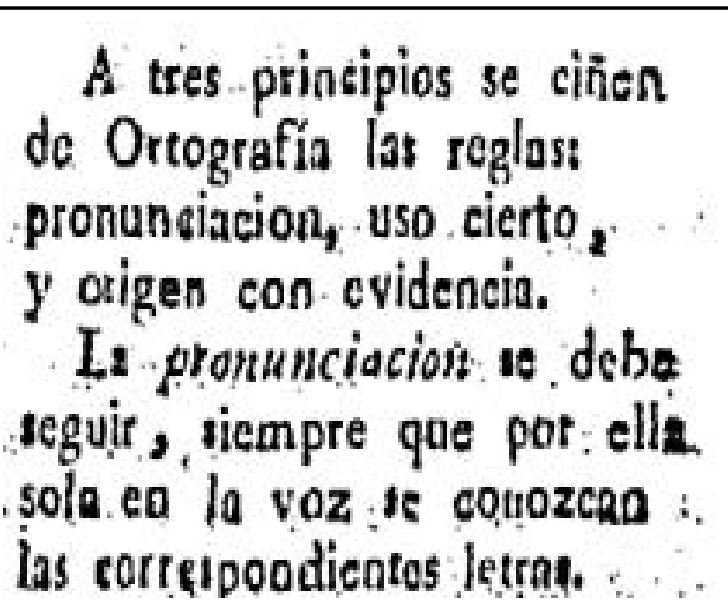 & 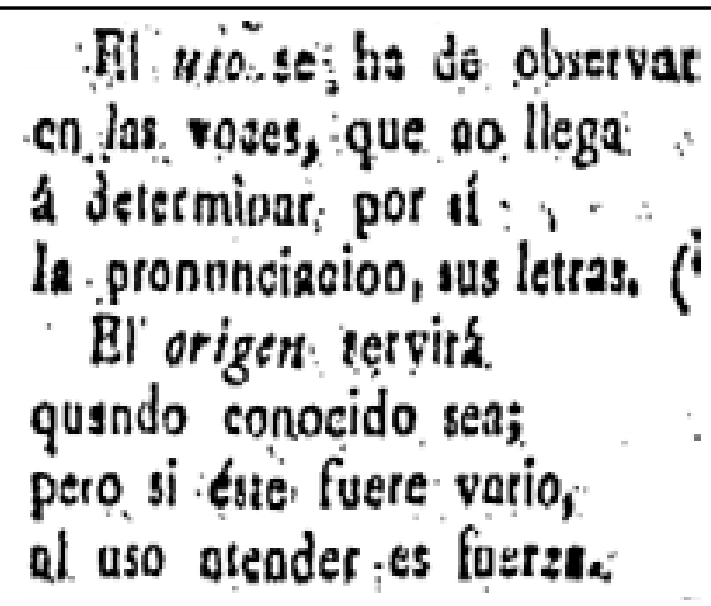 \\
\hline
\end{tabular}

Sin embargo, la polémica no fue superada por el simple hecho de que el grupo criollo que pugnaba por un uso propio de la lengua española oral y escrita entendía que la lengua era un espacio más hacia donde podían extender su inconformidad y no su incapacidad para ajustarse a la normatividad lingüística.

La polémica gira en torno a dos posiciones: uno de los grupos criollos opina que los criollos deben hablar el idioma de "sus mayores", entendidos estos como los peninsulares, pues son quienes han traído la lengua. Consideran que en la Nueva España se habla un español deficiente. Dicen además con entusiasmo que es necesario asemejar la lengua a la "verdadera lengua castellana" (DM, 2 de octubre de 1805: 166), y critican a quienes se niegan a ajustarse a la norma española, y así sentencian que quien quiera mantenerse en sus usos viciosos, "Que se contente con su amada costumbre y si aún ésta les parece rigurosa, váyase a habitar entre los apaches” (DM, 28 de septiembre de 1807: 109).

Por su parte, al segundo grupo criollo le parece que forzar la pronunciación castellana en la Nueva España pasa como "pedantería y ridiculez" (DM, 4 de diciembre de 1805: 275), práctica forzada de imitación que "es capaz de chocar y lastimar los oídos de un herrero", pues a la pronunciación de este dialecto no se han acostumbrado desde la niñez, por ello incurren en "mil desatinos" (DM, 5 de septiembre de 1807: 18), por tanto, es innecesario el empeño de enseñar la pronunciación de la c, z, ll e y para pronunciar como en las dos Castillas (DM, 24 de mayo de 1806: 99), debido a que "cada nación tiene su modo característico [de pronunciar] que la distingue y, por lo mismo, [dicen] a la nuestra no se le debe reprobar el suyo porque no se parece al de Madrid, ni hay tampoco un fundamento racional para ello"(DM, 6 de septiembre de 1806: 22). 
Los polemistas que suscriben esta posición sobre la lengua, rechazan expresamente que "todas las cosas de España sean mejores que las nuestras” (DM, 2 de junio de 1806: 149), por lo que piensan que es "imprudencia y pedantería...la de quienes quieren, con su modo de pronunciar, trastornan la constitución nacional de nuestro idioma” (DM, 18 de julio de 1806: 322). Denuncian más adelante en el mismo texto que quienes adoptan la forma de pronunciar castellana incurren en una especie de deslealtad y que estos personajes: "al no poder desnudarse de la cualidad de criollos, como que se avergüenzan de serlo, se despojan del más perceptible distintivo cual es el de la pronunciación", hecho que demerita la identidad criolla, larga y dificultosamente construida. Concluyen que con esa actitud perjudican a ese sector de la sociedad, por lo que reclaman a los criollos que optan por sujetarse al dominio español: “No ven pues, que ellos mismos se envilecen con esto! Dan a entender que es vil y despreciable el criollismo” (DM, 18 de julio de 1806: 323).

Por lo anterior, y puesto que se trata de dos formas distintas de hablar, los americanos deben "cuidar de escribir el castellano bien, sin apartarnos en la pronunciación de nuestro estilo nacional” (DM, 18 de julio de 1806: 323), esto es, reformar la ortografía para ajustarla a las necesidades propias ${ }^{14}$. Al mismo tiempo, este grupo criollo intenta distinguir su habla de la del grupo poblacional mayoritario, el mestizo e indígena, cuando se dice que "ese es un lenguaje grosero, insignificante, sólo usado por gente idiota y rústica” (DM, 4 de diciembre de 1805: 275).

Ambas opiniones respecto de la lengua hablada por otros grupos ajenos al ámbito criollo, se ajustan a lo expresado por Francisco López Cámara en su estudio sobre la sociedad criolla cuando dice que el criollo "No quiere ser europeo o indio, sino distinto a ambos" (López Cámara, 1969: 27 ). Finalmente, aparece en el debate un tercer grupo que reclama el derecho a participar en la discusión y defiende el habla popular. Este grupo es denostado y caricaturizado por la mayoría criolla que participa en el Diario, pues considera que esta publicación es vehículo exclusivo de difusión del pensamiento criollo. Es el instrumento con que se autoproclama como el más apto para encabezar la sociedad, pues considera que ha ganado por derecho propio ese deber. De ahí que incluir y dar cabida e importancia a opiniones de otros grupos, por ejemplo, los indios, contribuiría a fortalecer a esos grupos y forjarse con ello un competidor en la lucha por el poder que se avecina en los años siguientes.

Por tanto, la proclamación y demanda de los derechos a su propia lengua en la discusión en el Diario de México es un mero acto político que apunta a la conformación de un nuevo régimen, más que a una nueva lengua. Las demandas de respeto y legitimidad a los rasgos de pronunciación, ortografía, léxico (y construcción sintáctica, pocas veces mencionado, por cierto) son demandas de reconocimiento que caen en el terreno de la acción política, más que en la lingüística; esta última

14. Una propuesta que también resurgirá algunas décadas después en la polémica antes mencionada, la producida entre Andrés Bello y Sarmiento. Esta polémica se desarrolló prácticamente en los mismos términos: demanda de respeto a los usos americanos, instigar el apego a la norma castellana, promover la guía de los usos cultos como modelo normativo, propuesta de una reforma ortográfica que se ajustara al habla americana, incluso, las críticas y burlas a quienes esforzaban, con poco éxito, un afectado y autoimpuesto uso de la lengua. 
ya se ha concretado (Company, 2007: 18) con la simple dinámica evolutiva de la lengua en la Nueva España, con poca intervención consciente de los hablantes americanos.

A partir de la tercera década del siglo XIX, cuando las naciones que conformaron la Nueva España habían alcanzado su independencia, continuaron los esfuerzos por desligarse del control de España y la Academia sobre la lengua española hablada en América. Sin embargo, no podría decirse que estos esfuerzos estén directamente ligados a los que se presentaron en el periodo colonial y que quedaron plasmados en la discusión analizada en estas páginas. Los motivos de esta afirmación son varios. En primer lugar, el grupo criollo que puede reconocerse a partir de sus escritos como defensor del habla americana, también es el que intenta separarse de los otros grupos sociales que componen la sociedad. En el panorama colonial, tal propósito era viable de alcanzar, dados los privilegios que poseían los criollos como la parte más alta de la escala social, pero en el periodo independiente, la disposición de fuerzas cambia y ese grupo tiene que competir con otros grupos sociales en condiciones más equivalentes.

Por otra parte, el grupo que llega al poder al término de la revolución de independencia es el más conservador y, por tal motivo, intenta mantener sus lazos con la tradición cultural hispánica. Avanzado el siglo XIX, surgen dos factores de carácter político que frenan en México la tajante separación de lo español, como se proponía en la polémica: por una parte, la presencia de Estados Unidos como potencia amenazante, lo que orilla nuevamente a intelectuales y políticos a buscar recaudo en España y Latinoamérica. Por otra parte, las dificultades que enfrenta el país como nación nueva y la inestabilidad social y política impiden que se diseñen políticas lingüísticas y educativas eficientes. En este aspecto, las políticas lingüísticas se limitan a la castellanización del país único como medio de promover el desarrollo.

\section{Conclusión}

La exclusión del criollo provocó que este grupo cimentara una identidad propia. Ese proceso de toma de conciencia pasó por tres etapas: en primer lugar, cuando desde los primeros años se hizo distinción de la población blanca nacida en España y la nacida en América; en segundo lugar, continúa con un tímido reconocimiento por parte del criollo de que efectivamente hay diferencias entre ambos, finalmente, cuando se consolida su identidad al ser excluido de manera abierta, y decide emprender su tarea de reivindicación y toma plena conciencia de sí.

Es entonces que para lograr su propósito fortaleció sus vínculos al interior y construyó una narrativa de su origen y futuro en la sociedad novohispana. Una de las formas de identificarse fue la lengua española hablada en la Nueva España. A ese respecto, el criollo se dividió en dos opiniones: ajustar su habla a la realizada en la Península, específicamente, a la norma de Madrid o hacer uso del español con las particularidades americanas. Centra su atención en los rasgos más visibles de la pronunciación, el seseo y el yeísmo principalmente, y hace de su uso una acción política que le sirve 
para tomar posición con respecto al régimen en el poder. Por otro lado, hace dos deslindes: primero, no quiere ser español ahora que ha entendido que no es incluido con igualdad de derechos; segundo, no todos los americanos son iguales, por ello intenta distinguirse de las mayorías hablantes de español, indios y mestizos, cuyas hablas califica de idiotas. Para fortalecer esta separación entre dos tipos de americanos, los criollos y los indios y mestizos, caricaturiza a estos últimos retratando los rasgos de su habla con la intención de demeritar sus capacidades, y dadas las deficiencias de otros grupos, se autoproclama como el más indicado para encabezar una sociedad futura. 


\section{Bibliografía}

Brading, David A. (1973), Los orígenes del nacionalismo mexicano, México, Secretaría de Educación Pública.

Company, Concepción (2007), El siglo XVIII y la identidad lingüística de México, México, Universidad Nacional Autónoma de México-Academia Mexicana de la Lengua.

Diario de México, 8 volúmenes, 1805-1808.

Florescano, Enrique e Isabel Gil (1998), "La época de las reformas borbónicas y el crecimiento económico, 1750-1808”, en Historia general de México I, México, El colegio de México, p. 471-589.

Florescano, Enrique y Rafael Rojas (1996), El ocaso de la Nueva España, México, Clío.

López Cámara, Francisco (1969), La génesis de la conciencia liberal en México, México, UNAM.

Martínez Luna, Ester (2002), Estudio e índice onomástico del Diario de México: primera época, 18051812, México, Universidad Nacional Autónoma de México-Instituto de Investigaciones Filológicas.

Mier, Servando Teresa de (1982), "Sermón guadalupano", en Ernesto de la Torre Villar y Ramiro Navarro de Anda (eds.), Testimonios históricos guadalupanos, México, Fondo de Cultura Económica, p. $730-757$.

Moreno Bonett, Margarita (2000), Nacionalismo novohispano, México, DF, Universidad Nacional Autónoma de México.

O’Gorman, Edmundo (1972), "Prólogo”, en Fernando de Alva Ixtlixóchitl, Nezahualcóyotl Acolmixtli, México, Gobierno del Estado de México.

Ruíz Castañeda, Carmen (2000), Diccionario de seudónimos, anagramas, iniciales y otros alias usados por escritores mexicanos y extranjeros que han publicado en México, México, Universidad Nacional Autónoma de México-Instituto de Investigaciones Filológicas.

Van Dijk, Teun (2006), Ideología: una aproximación multidisciplinaria, Sevilla, Gedisa.

Villoro, Luis (2002), El proceso ideológico de la revolución de independencia, México, Consejo Nacional para la Cultura y las Artes. 